\title{
Lactoferrin Protects Human Mesenchymal Stem Cells from Oxidative Stress-Induced Senescence and Apoptosis
}

\author{
Soon Yong Park ${ }^{1 \dagger}$, Ae-Jin Jeong ${ }^{1,2 \dagger}$, Geun-Young Kim ${ }^{3 \dagger}$, Ara Jo ${ }^{1}$, Joo Eon Lee ${ }^{1}$, Sun-Hee Leem ${ }^{1}$, Joung-Hahn Yoon ${ }^{4}$, \\ Sang Kyu Ye ${ }^{2}$, and Jin Woong Chung ${ }^{1 *}$ \\ ${ }^{1}$ Department of Biological Science, Dong-A University, Busan 49315, Republic of Korea \\ ${ }^{2}$ Department of Pharmacology and Biomedical Sciences, College of Medicine, Seoul National University, Seoul 03080, Republic of Korea \\ ${ }^{3}$ Jeju National Quarantine Station, Centers for Disease Control E Prevention, Jeju 63219, Republic of Korea \\ ${ }^{4}$ Department of Mathematics, Dong-A University, Busan 49315, Republic of Korea
}

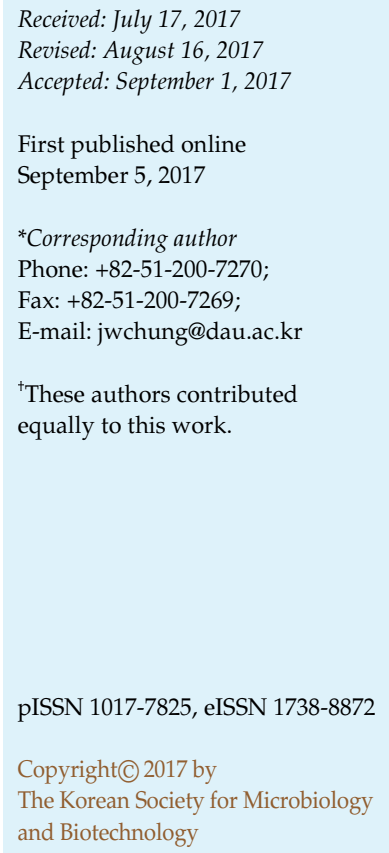

\begin{abstract}
Mesenchymal stem cells (MSCs) have been suggested as a primary candidate for cell therapy applications because they have self-renewal and differentiation capabilities. Although they can be expanded in ex vivo system, clinical application of these cells is still limited because they survive poorly and undergo senescence or apoptosis when transplanted and exposed to environmental factors such as oxidative stress. Thus, reducing oxidative stress is expected to improve the efficacy of MSC therapy. The milk protein lactoferrin is a multifunctional ironbinding glycoprotein that plays various roles, including reduction of oxidative stress. Thus, we explored the effect of lactoferrin on oxidative stress-induced senescence and apoptosis of human MSCs (hMSCs). Measurement of reactive oxygen species (ROS) revealed that lactoferrin inhibited the production of hydrogen peroxide-induced intracellular ROS, suggesting lactoferrin as a good candidate as an antioxidant in hMSCs. Pretreatment of lactoferrin suppressed hydrogen peroxide-induced senescence of hMSCs. In addition, lactoferrin reduced hydrogen peroxide-induced apoptosis via inhibition of caspase-3 and Akt activation. These results demonstrate that lactoferrin can be a promising factor to protect hMSCs from oxidative stress-induced senescence and apoptosis, thus increasing the efficacy of MSC therapy.
\end{abstract}

Keywords: Apoptosis, lactoferrin, mesenchymal stem cells, oxidative stress, senescence

\section{Introduction}

Mesenchymal stem cells (MSCs) are heterogenous subsets of stromal stem cells characterized by self-renewal and pluripotent differentiation capabilities toward the mesodermal lineage cells, such as chondrocytes, adipocytes, myocytes, and osteocytes [1]. MSCs have been suggested as a primary candidate for cell therapy because of their easy isolation, expansion, and preservation [2-6]. Currently, clinical trials of MSC therapy are being performed in several diseases, including cardiovascular and neurological diseases [7-9]. For the clinical use of MSCs, prolonged ex vivo expansion should be achieved because of the low prevalence of MSCs in the primary tissue [9]. However, when the expanded
MSCs are transplanted to the target tissue, they are exposed to several environmental factors, such as oxidative stress, leading to senescence and apoptosis of MSCs and hindering their clinical application [10-14]. Thus, reducing oxidative stress is expected to improve the efficacy of MSC therapy. Lactoferrin, a protein present mainly in mammalian milk, is a pleiotrophic glycoprotein and a member of the transferrin family [15]. It is synthesized by glandular epithelial cells and plays a role in iron homeostasis, antiinflammation, and host defense against microbial infection [16]. Interestingly, previous studies showed that lactoferrin reduced the level of reactive oxygen species (ROS), suggesting that lactoferrin may have great potential in MSC therapy as an antioxidant [17-19]. Thus, in this study, we investigated 
the effect of lactoferrin on the suppression of oxidative stress-induced senescence and apoptosis of human MSCs (hMSCs). Hydrogen peroxide is one of the main sources of intracellular ROS, and thus we treated hMSCs with hydrogen peroxide to induce oxidative stress, and examined the levels of senescence and apoptosis by measuring senescenceassociated $\beta$-galactosidase (SA- $\beta$-galactosidase) activity and the amount of Annexin-V-positive apoptotic cells, respectively, with or without pretreatment with lactoferrin. Our results demonstrate that lactoferrin efficiently lowered the level of intracellular ROS, and suppressed senescence and apoptosis of hMSCs via inhibition of caspase-3 and Akt activation. These results suggest that lactoferrin may be an efficient factor that can increase the efficacy of MSC therapy.

\section{Materials and Methods}

\section{Cell Culture and Reagents}

Cryopreserved hMSCs were obtained from Lonza (USA). The cells were grown in Minimum Essential Medium- $\alpha$ (MEM- $\alpha$; Invitrogen, USA) supplemented with $10 \%$ fetal bovine serum (Hyclone, USA) and penicillin/streptomycin (100 U/ml; HyClone). Cells were used at passages 2 to 10 and grown at $37^{\circ} \mathrm{C}$ in a humidified incubator with $5 \% \mathrm{CO}_{2}$. Hydrogen peroxide and lactoferrin were purchased from Sigma (USA). Pan-caspase inhibitor, Z-VAD-FMK, was purchased from R\&D Systems (USA).

\section{Viable Cell Number Counting}

Cells were seeded into 24 -well cell culture plates at the density of $2 \times 10^{4}$ cells/well. The cells were stimulated with hydrogen peroxide for $2 \mathrm{~h}$ to induce oxidative stress, washed with PBS, and incubated in complete medium for $24 \mathrm{~h}$. Then, the cells were trypsinized and the viable cell numbers were counted using a hemocytometer under an optical microscope. In some experiments, cells were incubated with lactoferrin for $24 \mathrm{~h}$ prior to stimulation with hydrogen peroxide.

\section{Senescence-Associated $\beta$-Galactosidase Staining}

Cells were stimulated with hydrogen peroxide for $2 \mathrm{~h}$ to induce oxidative stress, washed with PBS, and incubated in complete medium for $72 \mathrm{~h}$. Then, the cells were washed with PBS and fixed in $0.2 \%$ glutaraldehyde for $15 \mathrm{~min}$ at room temperature. The cells were washed with PBS and incubated with SA- $\beta$-galactosidase staining solution (BioVision, USA) at $37^{\circ} \mathrm{C}$ for $16 \mathrm{~h}$. The development of a blue color in cells was observed under a microscope. In some experiments, cells were incubated with lactoferrin for $24 \mathrm{~h}$ prior to stimulation with hydrogen peroxide.

\section{Measurement of Intracellular Reactive Oxygen Species}

Cells were treated with lactoferrin for $24 \mathrm{~h}$ and stimulated with hydrogen peroxide for $2 \mathrm{~h}$. ROS-sensitive DCF-DA $\left(2^{\prime}, 7^{\prime}\right.$ dichlorofluorescin diacetate; Sigma Aldrich; $20 \mu \mathrm{M}$ ) was added for the last $30 \mathrm{~min}$ and the samples were then immediately analyzed with a fluorescence microscope. For quantification of ROS generation, spectrofluorimetry was performed with a Fluostar Optima spectrofluorimeter (BMG Technologies, USA) following the manufacturer's instructions. Briefly, $3 \times 10^{6}$ cells were suspended in $1 \mathrm{ml}$ of serum-free MEM- $\alpha$ and labeled with $10 \mu \mathrm{M}$ of DCF-DA for $10 \mathrm{~min}$ at $37^{\circ} \mathrm{C}$. The cells are washed twice with serum-free medium and resuspended in $750 \mu \mathrm{l}$ of medium. Then, $100 \mu \mathrm{l}$ of the suspension was pipetted in each well of the 96-well microplate supplied by the manufacturer (BMG Technologies). The fluorescence was measured with the Fluostar Optima spectrofluorimeter. The filters used for fluorescence measurement were for an absorption spectrum of $485 \mathrm{~nm}$ and emission spectrum of $520 \mathrm{~nm}$.

\section{Apoptosis Assay}

Cells were pretreated with lactoferrin for $24 \mathrm{~h}$ or Z-VAD-FMK for $1 \mathrm{~h}$ and stimulated with hydrogen peroxide for $2 \mathrm{~h}$. Then, the cells were washed with PBS and further incubated in complete medium for $24 \mathrm{~h}$. The apoptotic percentage was determined with a Muse Annexin V \& Dead cell kit (Millipore, USA) using a Muse Cell analyzer according to the manufacturers' instructions. The activity of caspase-3 was determined with a Muse Caspase-3/7 kit (Millipore) according to the manufacturers' instructions.

\section{Western Blot Analysis}

Cells were lysed in lysis buffer (20 mM Tris- $\mathrm{HCl}$ (pH 6.8), $150 \mathrm{mM}$ $\mathrm{NaCl}, 1 \mathrm{mM}$ EDTA, $1 \mathrm{mM}$ EGTA, 1\% TritonX-100) containing a protease inhibitor (complete-Mini; Roche) for $20 \mathrm{~min}$ on ice, and then centrifugated at $13,000 \times g$ for $20 \mathrm{~min}$ at $4^{\circ} \mathrm{C}$. Twenty milligrams of the proteins was resolved on $12 \%$ sodium dodecyl sulfatepolyacrylamide gels and transferred to polyvinylidene difluoride membranes. The membranes were incubated sequentially with primary antibodies and HRP-conjugated secondary antibodies. Immunoreactivity was detected with Enhanced Peroxidase Detection (ELPIS Biotec. Inc) on X-ray film (Sigma-Aldrich).

\section{Statistical Analysis}

All experiments were repeated at least three times. Data are presented as the mean \pm standard deviation. Analyses were performed with the Student's $t$-test and values of $p<0.05$ were considered significant.

\section{Results}

\section{Effect of Hydrogen Peroxide on hMSC Senescence and Viability}

Since hydrogen peroxide has been frequently used to induce oxidative stress in various cell types, including MSCs [20], we first examined the optimal concentration of hydrogen peroxide that induced senescence and reduced the cell viability. We treated hMSCs with increasing concentrations of hydrogen peroxide and performed SA- $\beta$ - 
A

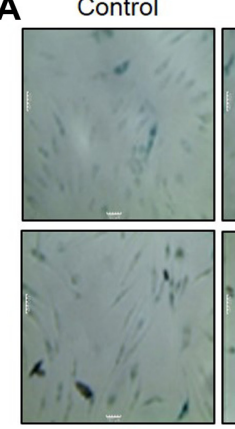

200
100
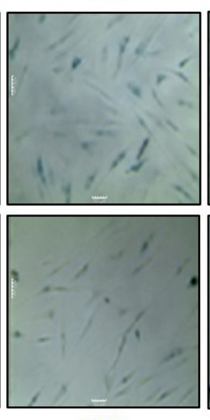

250
150

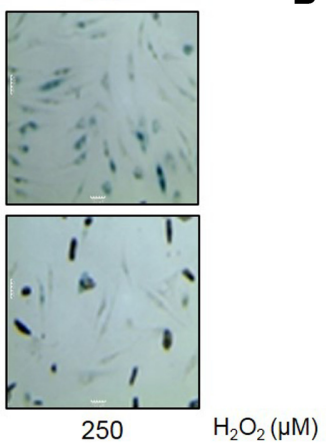

B

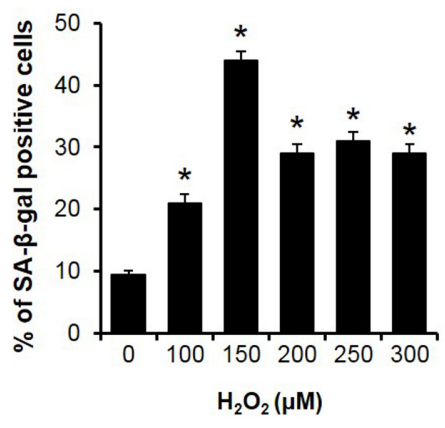

C

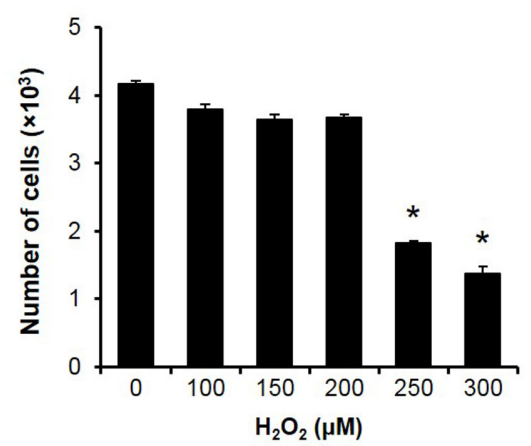

D

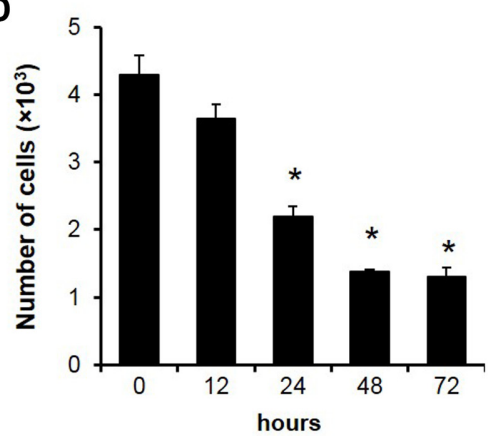

Fig. 1. Hydrogen peroxide induces the senescence and decreases the viability of hMSCs.

(A) Effects of hydrogen peroxide on the senescence of hMSCs. hMSCs were stimulated with the indicated concentrations of hydrogen peroxide for $2 \mathrm{~h}$, and senescence-associated $\beta$-galactosidase (SA-associated $\beta$-galactosidase) staining was performed as described in Materials and Methods. (B) SA- $\beta$-galactosidase stain-positive cells were enumerated and expressed as a percentage of total cell counts. ${ }^{*} p<0.05$ versus no hydrogen peroxide treatment. (C) Dose-dependent effects of hydrogen peroxide on viability of hMSCs. hMSCs $\left(2 \times 10^{4}\right.$ cells/well $)$ were treated with indicated concentrations of hydrogen peroxide for $2 \mathrm{~h}$, and the number of viable cells was counted after $24 \mathrm{~h}$ incubation. ${ }^{*} p<0.05$ versus no hydrogen peroxide treatment. (D) Time-dependent effects of hydrogen peroxide on the viability of hMSCs. Cells $\left(2 \times 10^{4}\right.$ cells/well $)$ were treated with $250 \mu \mathrm{M}$ hydrogen peroxide, and further incubated in complete medium for indicated times after washing with PBS. Then, the number of viable cells was counted. The results are averages of three independent experiments $\left.{ }^{*} p<0.05\right)$.

galactosidase staining. As shown in Figs. $1 \mathrm{~A}-1 \mathrm{~B}$, hydrogen peroxide significantly increased the SA- $\beta$-galactosidase stain- positive cells with a peak at $150 \mu \mathrm{M}$. Next, we seeded the same number of hMSCs and treated them with increasing concentrations of hydrogen peroxide. Although the low concentrations of hydrogen peroxide $(100,150$, and $200 \mu \mathrm{M})$ had little effect on the viability of hMSCs, the higher concentrations of hydrogen peroxide $(250$ and $300 \mu \mathrm{M})$ reduced the viability by more than $50 \%$ (Fig. 1C). In addition, we treated hMSCs with $250 \mu \mathrm{M}$ hydrogen peroxide for the increasing time and found that hydrogen peroxide reduced the hMSC viability in a time-dependent manner (Fig. 1D). These results demonstrated that hydrogen peroxide induces both cell death and senescence in hMSCs depending on the concentrations, which is consistent with a previous report showing that lethal concentrations of hydrogen peroxide induce apoptosis whereas sublethal concentrations of hydrogen peroxide induce senescence in human diploid fibroblasts [21].

\section{Lactoferrin Decreases the Level of Intracellular ROS}

Previous studies showed that lactoferrin played an important role in reducing ROS generation in dexamethasoneinduced hypertension and pollen antigen-induced airway inflammation $[18,19]$. Thus, we hypothesized that lactoferrin could be a good candidate to reduce the level of ROS and maintain the therapeutic potential of hMSCs. To examine whether lactoferrin decreased the level of ROS in hMSCs, we incubated the cells with lactoferrin for $24 \mathrm{~h}$ prior to stimulation with $150 \mu \mathrm{M}$ hydrogen peroxide. DCF-DA staining assays showed that the $150 \mu \mathrm{M}$ hydrogen peroxide treatment increased the level of ROS in hMSCs, as expected. 
A
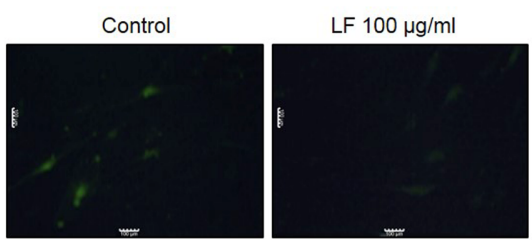

$\mathrm{H}_{2} \mathrm{O}_{2} 150 \mu \mathrm{M}$

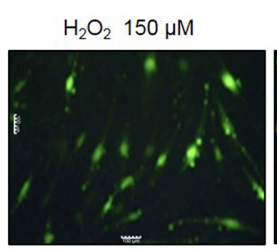

C

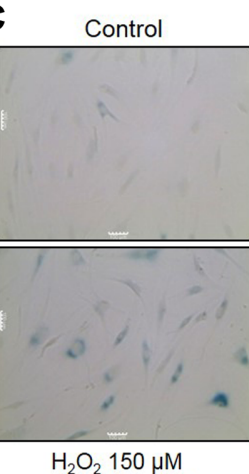

$+\mathrm{LF} 10 \mu \mathrm{g} / \mathrm{ml}$
$+\mathrm{LF} 100 \mu \mathrm{g} / \mathrm{ml}$

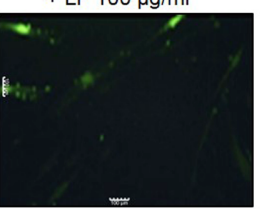

$\mathrm{LF} 100 \mu \mathrm{g} / \mathrm{m} \ell$

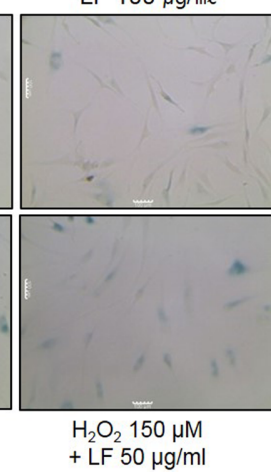

$\mathrm{H}_{2} \mathrm{O}_{2} 150 \mu \mathrm{M}$

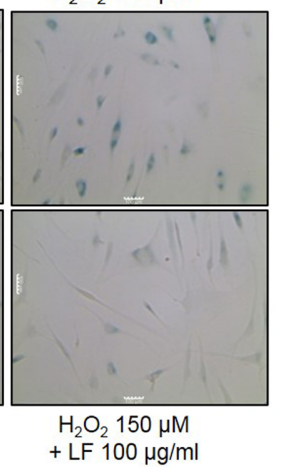

B

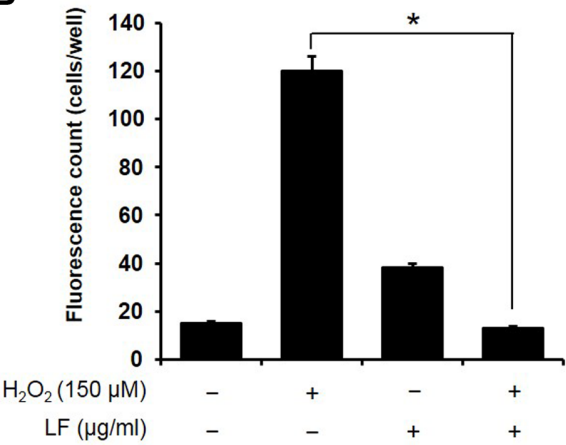

Fig. 2. Lactoferrin suppresses hydrogen peroxide-induced intracellular ROS production and cellular senescence in hMSCs.

(A) Microscopic analysis of the inhibitory effect of lactoferrin (LF) on ROS production. (B) Quantification of ROS production. The intensity of DCF fluorescence, reflecting the level of intracellular ROS, was analyzed using ImageJ software, and relative intensity to the control (no treatment) is shown. The results are averages of three independent experiments $\left({ }^{*} p<0.05\right)$. (C) Microscopic analysis of the inhibitory effect of LF on senescence of hMSCs. hMSCs were stimulated with $150 \mu \mathrm{M}$ hydrogen peroxide for $2 \mathrm{~h}$ after pretreatment with the indicated concentration of LF for $24 \mathrm{~h}$. After $72 \mathrm{~h}$ incubation in complete medium, senescence-associated $\beta$-galactosidase (SA-associated $\beta$-galactosidase) staining was performed as described in Materials and Methods. (D) Quantification of SA- $\beta$-galactosidase stain-positive cells. SA- $\beta$-galactosidase stain-positive cells were enumerated and expressed as a percentage of total cell counts. The results are averages of three independent experiments $\left({ }^{*} p<0.05\right.$ versus no treatment; ${ }^{* *} p<0.05$ versus hydrogen peroxide treatment).

However, pretreatment with lactoferrin decreased the level of ROS (Figs. 2A and 2B), demonstrating that lactoferrin played a role as an antioxidant in hMSCs.

\section{Lactoferrin Decreases the Hydrogen Peroxide-Induced Senescence of hMSCs}

Senescence is irreversible growth arrest and makes hMSCs lose their self-renewal capability, limiting their applications to clinical therapy [13]. One of the important factors that induce hMSC senescence is oxidative stress [12]. Thus, we examined whether lactoferrin could inhibit oxidative stress-induced senescence. Because we found that $150 \mu \mathrm{M}$ hydrogen peroxide most efficiently induced the senescence of hMSCs (Figs. 1A and 1B), we treated cells with $150 \mu \mathrm{M}$ hydrogen peroxide after pretreatment with increasing concentrations of lactoferrin. SA- $\beta$-galactosidase staining revealed that lactoferrin suppressed the hydrogen peroxideinduced senescence of hMSCs (Figs. 2C and 2D).

\section{Lactoferrin Decreases the Hydrogen Peroxide-Induced Apoptosis of hMSCs}

Besides senescence, apoptosis of MSCs during expansion or after transplantation is the bottleneck to be overcome for efficient clinical use of MSCs [1,9]. Although apoptosis of MSCs is not fully understood, previous studies suggested that oxidative stress is the main cause [22]. Because we found that $250 \mu \mathrm{M}$ hydrogen peroxide efficiently decreased the viability of hMSCs (Fig. 1C), we treated cells with $250 \mu \mathrm{M}$ hydrogen peroxide after pretreatment with increasing concentrations of lactoferrin, and examined the hMSC viability. As shown in Fig. 3A, lactoferrin suppressed the hydrogen peroxide-induced cell death of hMSCs in a 
A

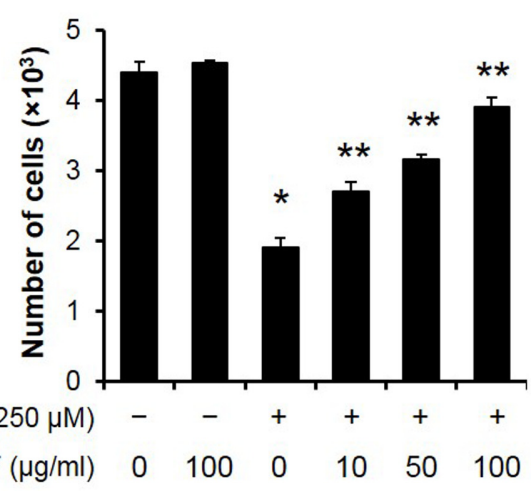

C

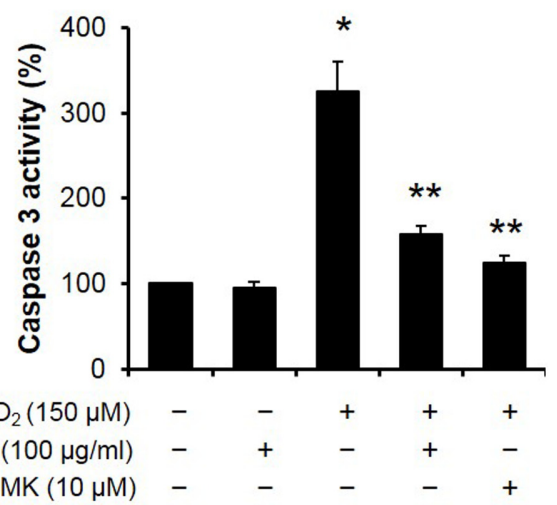

B
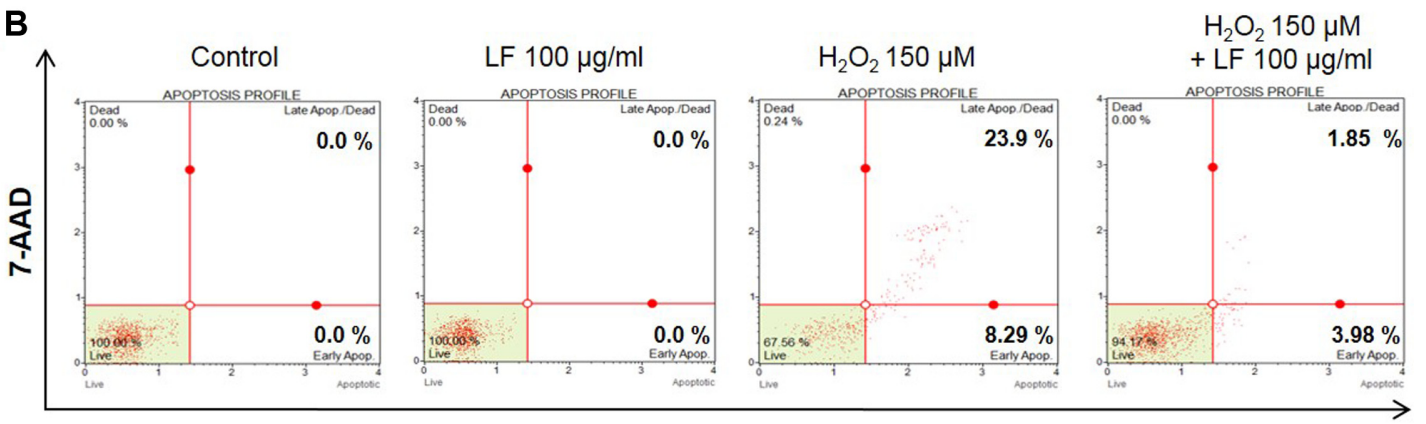

Annexin-V

Fig. 3. Lactoferrin suppresses hydrogen peroxide-induced apoptosis of hMSCs.

(A) hMSCs were seeded into 24-well cell culture plates at the density of $2 \times 10^{4}$ cells/well. Next day, cells were treated with the indicated concentrations of lactoferrin (LF) for $24 \mathrm{~h}$. The cells were then stimulated with hydrogen peroxide $(250 \mu \mathrm{M})$ for $2 \mathrm{~h}$, washed with PBS, and further incubated in complete medium for $24 \mathrm{~h}$. Then, the cells were trypsinized and the number of viable cells was counted; ${ }^{*} p<0.05$ versus no treatment. ${ }^{* *} p<0.05$ versus hydrogen peroxide treatment. (B) hMSCs were treated with $\mathrm{LF}(100 \mu \mathrm{g} / \mathrm{ml})$ for $24 \mathrm{~h}$. Then, the cells were stimulated with the hydrogen peroxide $(250 \mu \mathrm{M})$ for $2 \mathrm{~h}$, washed with PBS, and further incubated in complete medium for $24 \mathrm{~h}$. The apoptotic cells were analyzed using Muse Annexin V \& Dead cell kit as described in Materials and Methods. (C) hMSCs were treated with hydrogen peroxide $(250 \mu \mathrm{M})$ for $2 \mathrm{~h}$ after pretreatment with LF $(100 \mu \mathrm{g} / \mathrm{ml})$ for $24 \mathrm{~h}$ or Z-VAD-FMK $(10 \mu \mathrm{M})$ for $1 \mathrm{~h}$. The cells were washed with PBS and further incubated in complete medium for $24 \mathrm{~h}$. Then, the activity of caspase-3 was analyzed using the Muse Caspase-3/7 kit as described in Materials and Methods. The results are averages of three independent experiments $\left({ }^{*} p<0.05\right.$ versus no treatment; ${ }^{* *} p<0.05$ versus hydrogen peroxide treatment).

dose-dependent manner. To examine whether the reduced cell viability was caused by apoptosis, we performed Annexin $\mathrm{V}$ staining after treatment of hydrogen peroxide. As shown in Fig. 3B, hydrogen peroxide induced the apoptosis of hMSCs, and pretreatment with lactoferrin suppressed the hydrogen peroxide-induced apoptosis. Furthermore, we measured the hydrogen peroxide-induced activation of caspase-3 after pretreatment with lactoferrin or a pan-caspase inhibitor, Z-VAD-FMK. Caspase-3 activity assay revealed that lactoferrin suppressed the hydrogen peroxide-induced activation of caspase- 3 as comparable with the effect of Z-VAD-FMK (Fig. 3C), demonstrating lactoferrin can be a good candidate to reduce oxidative stress-induced apoptosis of hMSCs.

\section{Lactoferrin Inhibits ROS Generation Via AKT Activation}

Recent reports showed that inhibition of AKT induces cellular senescence and ROS generation in certain cell types [23-25]. Furthermore, a previous study showed that lactoferrin induces the phosphorylation of Akt in osteoblasts [26]. Because Akt is a key survival factor in various cell types [27], we examined the involvement of the Akt pathway in lactoferrin-induced hMSC survival. Our results showed that pretreatment with lactoferrin increased the hydrogen peroxide-induced phosphorylation of Akt compared with only hydrogen peroxide treatment (Fig. 4A). In addition, treatment of a PI3K/Akt inhibitor, Wortmannin, decreased the lactoferrin-induced inhibition of ROS generation (Figs. 4B and 4C) and cell survival (Fig. 4D) in hydrogen 
A

B

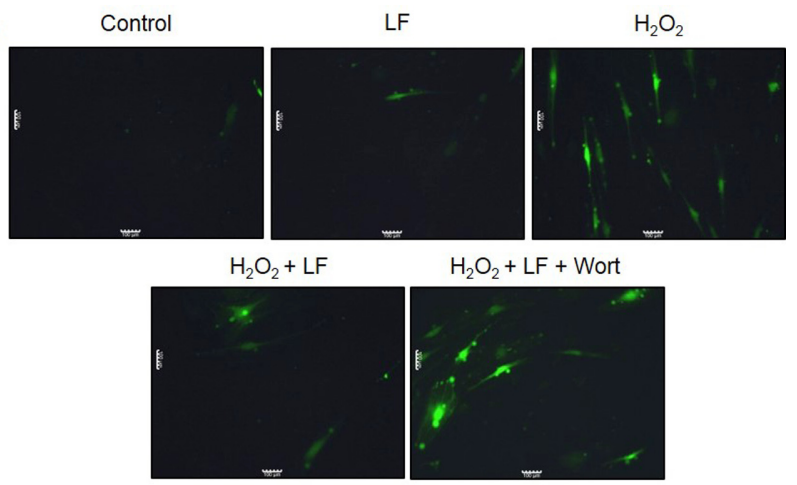

C

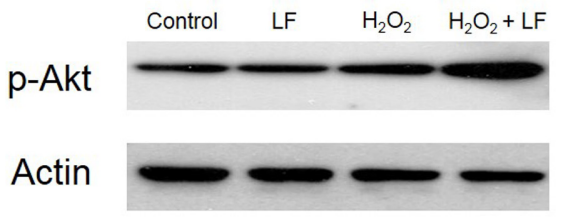

D
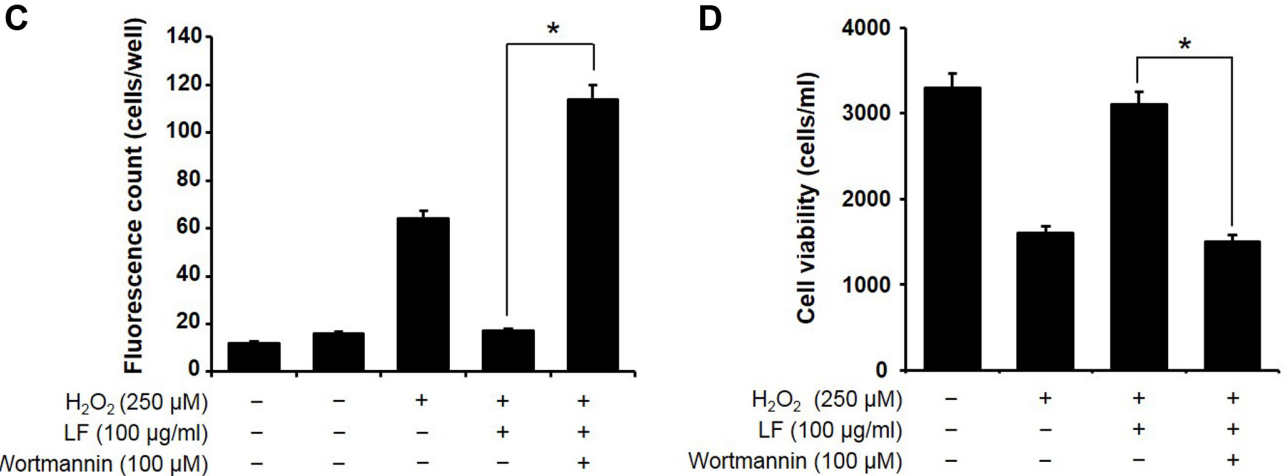

Fig. 4. Involvement of Akt in the lactoferrin-mediated protection from oxidative stress in hMSCs.

(A) Lactoferrin (LF)-induced Akt activation in $\mathrm{H}_{2} \mathrm{O}_{2}$-treated hMSCs was determined by western blotting. The image is a representative of three independent experiments. (B) hMSCs were pre-incubated with Wortmannin (Wort) (100 nM) for $2 \mathrm{~h}$ prior to incubation with LF for $24 \mathrm{~h}$, and then treated with $\mathrm{H}_{2} \mathrm{O}_{2}$. The cells were incubated with $20 \mu \mathrm{M}$ of ROS-sensitive dye DCF-DA and visualized using a fluorescent microscope. The image is a representative of three independent experiments (Magnification, 400x). (C) For quantification of ROS production, the intensity of DCF fluorescence was analyzed using ImageJ software. The results are averages of three independent experiments $\left({ }^{*} p<0.05\right)$. (D) Effect of Akt inhibitor (Wortmannin) on LF-mediated protection of $\mathrm{H}_{2} \mathrm{O}_{2}$-induced cell apoptosis of hMSCs. hMSCs were stimulated with $250 \mu \mathrm{M}$ hydrogen peroxide for an indicated time after treatment with lactoferrin $(100 \mu \mathrm{g} / \mathrm{ml})$ for $24 \mathrm{~h}$ with or without pretreatment of Wortmanin (100 $\mathrm{nM})$ for $2 \mathrm{~h}$. The results are averages of three independent experiments $\left({ }^{*} p<0.05\right)$.

peroxide-treated hMSCs. These results suggest that Akt is a downstream target of lactoferrin in hMSCs for senescence or cell survival.

\section{Discussion}

ROS, a natural byproduct of normal metabolism, plays important roles of various cellular physiology, including cell signaling and homeostasis [28]. However, excessive ROS may cause oxidative stress, leading to significant damage to cell structures and functions. Thus, regulation of the cellular level of ROS is often a critical target for maintenance of cellular functions.

It has been reported that Akt activation may inhibit or induce ROS generation depending on the physiological conditions or cell types. For example, inactivation of Akt promotes ROS production and thus induces cellular senescence in leiomyoma cells [25], whereas knock-down of Akt in fibroblasts causes a decrease in ROS production but hyperactivation of Akt results in higher levels of ROS generation [29]. In this study, we found that lactoferrin inhibits ROS generation via Akt activation in hMSCs. Lactoferrin was first discovered in bovine milk as an ironcontaining protein, and later research revealed that the lactoferrin is also one of the major proteins in human milk [30]. Specifically, colostrum contains high levels of lactoferrin, and bovine colostrum itself has been known to be effective in treatment of certain infectious diseases [31, 32]. Interestingly, lactoferrin has also been reported to prevent several infections by boosting inflammatory responses in immune systems [33]. Since lactoferrin is a major protein in colostrum, the function of lactoferrin may play a main role in the therapeutic potentials of colostrum. In fact, lactoferrin has previously been reported to suppress 
the level of ROS both in vitro and in vivo in various cell types and animal models [17-19,34]. However, there is no study investigating its antioxidant function in hMSCs. Thus, this study is the first to show that lactoferrin plays an antioxidant role and reduces the oxidative stress-induced senescence and apoptosis of hMSCs, providing a therapeutic value of lactoferrin as a food reagent that increases the efficacy of MSC therapy.

\section{Acknowledgments}

This work was supported by the National Research Foundation of Korea (NRF-2012R1A1A2039992 and NRF2014R1A1A2059325).

\section{References}

1. Uccelli A, Moretta L, Pistoia V. 2008. Mesenchymal stem cells in health and disease. Nat. Rev. Immunol. 8: 726-736.

2. Colter DC, Class R, DiGirolamo CM, Prockop DJ. 2009. Rapid expansion of recycling stem cells in cultures of plastic-adherent cells from human bone marrow. Proc. Natl. Acad. Sci. USA 97: 3213-3218.

3. da Silva Meirelles L, Chagastelles PC, Nardi NB. 2006. Mesenchymal stem cells reside in virtually all post-natal organs and tissues. J. Cell Sci. 119: 2204-2213.

4. Lee MW, Yang MS, Park JS, Kim HC, Kim YJ, Choi J. 2005. Isolation of mesenchymal stem cells from cryopreserved human umbilical cord blood. Int. J. Hematol. 81: 126-130.

5. Sekiya I, Larson BL, Smith JR, Pochampally R, Cui JG, Prockop DJ. 2002. Expansion of human adult stem cells from bone marrow stroma: conditions that maximize the yields of early progenitors and evaluate their quality. Stem Cells 20: 530-541.

6. Kotobuki N, Hirose M, Takakura Y, Ohgushi H. 2004. Cultured autologous human cells for hard tissue regeneration: preparation and characterization of mesenchymal stem cells from bone marrow. Artif. Organs 28: 33-39.

7. Bang OY, Lee JS, Lee PH, Lee G. 2005. Autologous mesenchymal stem cell transplantation in stroke patients. Ann. Neurol. 57: 874-882.

8. Chen SL, Fang WW, Ye F, Liu YH, Qian J, Shan SJ, et al. 2004. Effect on left ventricular function of intracoronary transplantation of autologous bone marrow mesenchymal stem cell in patients with acute myocardial infarction. Am. J. Cardiol. 94: 92-95.

9. Parekkadan B, Milwid JM. 2010. Mesenchymal stem cells as therapeutics. Annu. Rev. Biomed. Eng. 12: 87-117.

10. Alekseenko LL, Zemelko VI, Domnina AP, Lyublinskaya OG, Zenin VV, Pugovkina NA, et al. 2014. Sublethal heat shock induces premature senescence rather than apoptosis in human mesenchymal stem cells. Cell Stress Chaperones 19: 355-366.
11. Zhu W, Chen J, Cong X, Hu S, Chen X. 2006. Hypoxia and serum deprivation-induced apoptosis in mesenchymal stem cells. Stem Cells 24: 416-425.

12. Brandl A, Meyer M, Bechmann V, Nerlich M, Angele P. 2011. Oxidative stress induces senescence in human mesenchymal stem cells. Exp. Cell Res. 317: 1541-1547.

13. Burova E, Borodkina A, Shatrova A, Nikolsky N. 2013. Sublethal oxidative stress induces the premature senescence of human mesenchymal stem cells derived from endometrium. Oxid. Med. Cell Longev. 2013: 474931.

14. Rodrigues M, Turner O, Stolz D, Griffith LG, Wells A. 2012. Production of reactive oxygen species by multipotent stromal cells/mesenchymal stem cells upon exposure to fas ligand. Cell Transplant. 21: 2171-2187.

15. Legrand D, Pierce A, Elass E, Carpentier M, Mariller C, Mazurier J. 2008. Lactoferrin structure and functions. Adv. Exp. Med. Biol. 606: 163-194.

16. Ward PP, Paz E, Conneely OM. 2005. Multifunctional roles of lactoferrin: a critical overview. Cell. Mol. Life Sci. 62: 2540-2548.

17. Kruzel ML, Actor JK, Radak Z, Bacsi A, Saavedra-Molina A, Boldogh I. 2010. Lactoferrin decreases LPS-induced mitochondrial dysfunction in cultured cells and in animal endotoxemia model. Innate Immun. 16: 67-79.

18. Kruzel ML, Bacsi A, Choudhury B, Sur S, Boldogh I. 2006. Lactoferrin decreases pollen antigen-induced allergic airway inflammation in a murine model of asthma. Immunology 119: 159-166.

19. Safaeian L, Zabolian H. 2014. Antioxidant effects of bovine lactoferrin on dexamethasone-induced hypertension in rat. ISRN Pharmacol. 2014: 943523.

20. Yagi H, Tan J, Tuan RS. 2013. Polyphenols suppress hydrogen peroxide-induced oxidative stress in human bone-marrow derived mesenchymal stem cells. J. Cell. Biochem. 114: 11631173.

21. Chen QM. 2000. Replicative senescence and oxidant-induced premature senescence. Beyond the control of cell cycle checkpoints. Ann NY Acad Sci. 908: 111-125.

22. Mohammadzadeh M, Halabian R, Gharehbaghian A, Amirizadeh N, Jahanian-Najafabadi A, Roushandeh AM, Roudhenar MH. 2012. Nrf-2 overexpression in mesenchymal stem cells reduces oxidative stress-induced apoptosis and cytotoxicity. Cell Stress Chaperones 17: 553-565.

23. Kennedy AL, Morton JP, Manoharan I, Nelson DM, Jamieson NB, Pawlikowski JS, et al. 2011. Activation of the PIK3CA/AKT pathway suppresses senescence induced by an activated RAS oncogene to promote tumorigenesis. Mol. Cell 42: 36-49.

24. Brunet A, Bonni A, Zigmond MJ, Lin MZ, Juo P, Hu LS, et al. 1999. Akt promotes cell survival by phosphorylating and inhibiting a Forkhead transcription factor. Cell 96: 857-868.

25. Xu X, Lu Z, Qiang W, Vidimar V, Kong B, Kim JJ, Wei JJ. 2014. Inactivation of AKT induces cellular senescence in uterine leiomyoma. Endocrinology 155: 1510-1519. 
26. Grey A, Zhu Q, Watson M, Callon K, Cornish J. 2006. Lactoferrin potently inhibits osteoblast apoptosis, via an LRP1-independent pathway. Mol. Cell. Endocrinol. 251: 96-102.

27. Sussman M. 2007. "AKT"ing lessons for stem cells: regulation of cardiac myocyte and progenitor cell proliferation. Trends Cardiovasc. Med. 17: 235-240.

28. Devasagayam T, Tilak JC, Boloor KK, Sane KS, Ghaskadbi SS, Lele RD. 2004. Free radicals and antioxidants in human health: current status and future prospects. J. Assoc. Physicians India 52: 796-804.

29. Nogueira V, Park Y, Chen CC, Xu PZ, Chen ML, Tonic I, et al. 2008. Akt determines replicative senescence and oxidative or oncogenic premature senescence and sensitizes cells to oxidative apoptosis. Cancer Cell 14: 458-470.
30. Sánchez L, Calvo M, Brock JH. 1992. Biological role of lactoferrin. Arch. Dis. Child. 67: 657-661.

31. Kelly GS. 2003. Bovine colostrums: a review of clinical uses. Altern. Med. Rev. 8: 378-394.

32. Struff WG, Sprotte G. 2008. Bovine colostrum as a biologic in clinical medicine: a review - Part II: clinical studies. Int. J. Clin. Pharmacol. Ther. 46: 211-225.

33. García-Montoya IA, Cendón TS, Arévalo-Gallegos S, Rascón-Cruz Q. 2012. Lactoferrin a multiple bioactive protein: an overview. Biochim. Biophys. Acta 1820: 226-236.

34. Park YG, Jeong JK, Lee JH, Lee YJ, Seol JW, Kim SJ, et al. 2013. Lactoferrin protects against prion protein-induced cell death in neuronal cells by preventing mitochondrial dysfunction. Int. J. Mol. Med. 31: 325-330. 